\title{
De América a Asia. El «otro viaje» de Alexander von Humboldt
}

\author{
por
}

Oliver Lubrich ${ }^{1}$

Universität Bern

En 1829 Alexander von Humboldt emprendió una expedición a Asia. Este segundo gran viaje del científico alemán fue complementario, en muchos sentidos, de su más conocido viaje a América, que realizó entre 1799 y 1804. En Rusia, Humboldt viajó y trabajó bajo una fuerte presión politica. En su Asie centrale (1843) se sirve de técnicas sutiles y de una crítica indirecta. Humboldt concluyó que, en una economía de monopolios estatales, generar energía era poco eficiente y causa de la destrucción del medio ambiente y del cambio climático.

Palabras Clave: Alexander von Humboldt; Rusia; expedición; orientalismo; politica; climatología.

Cómo Citar este artículo / Citation: Lubrich, Oliver, "De América a Asia. El «otro viaje» de Alexander von Humboldt", Revista de Indias, LXXIX/276 (Madrid, 2019): 497-520. https://doi.org/10.3989/revindias.2019.015.

Alexander von Humboldt emprendió dos grandes viajes: de 1799 a 1804 a través de las colonias españolas en América, y en 1829, por el imperio ruso, desde Europa hasta la frontera con $\mathrm{China}^{2}$. Su segunda travesía, menos conocida, puede entenderse en función de la primera, pues ambas se complementan en muchos aspectos.

Luego de haber explorado un imperio colonial de ultramar, Humboldt recorrió uno continental. El reino español se encontraba en plena erosión, previa, al triunfo de los movimientos de independencia, mientras que el ruso, estaba

1 oliver.lubrich@germ.unibe.ch, ORCID iD: https://orcid.org/0000-0002-0606-9493.

2 Antes de embarcarse rumbo a América, Humboldt viajó por la España peninsular y por Canarias. Véase: Puig-Samper y Rebok, 2007; 2002: 95-125. Puig-Samper, 2000. 
en medio de su restauración tras la derrota de los decabristas. Mientras en México y Perú apenas podían percibirse las tensiones de la metrópoli con otras naciones, el zar lideraba respectivas guerras en los Balcanes y en el Cáucaso contra el Imperio otomano y Persia. Si bien Humboldt había recorrido en Venezuela zonas ignotas, donde el Estado apenas intervenía, en Siberia se encontraría en un territorio sometido a un estricto control. Después de que en las colonias del rey español había podido transitar a discreción, en las provincias del Zar se encontró no solo bajo una permanente sospecha del poder, sino también bajo su influencia y vigilancia. Mientras que su expedición americana sirvió a sus propios intereses científicos, la asiática tenía objetivos económicos y políticos. Si por un lado el gobierno ruso esperaba de Humboldt, formado en ciencia de minas, información sobre la existencia y explotación de los bienes del subsuelo, el prusiano, por su parte, buscaba fortalecer las relaciones diplomáticas con tan poderoso vecino. La primera expedición fue financiada con medios propios; la segunda, con fondos externos. Tras haber regresado de América, Humboldt gozó en París de una relativa libertad de publicación, mientras que en Rusia y Prusia tuvo que someterse a la censura e incluso, más adelante, a la autocensura. Si bien por un lado había podido compartir con la opinión pública sus experiencias en América, el famoso descubridor redactó sus reportes al Ministro de Finanzas en Petersburgo con suma precaución, limitándose a expresar sus críticas en privado, en cartas a su hermano o en anotaciones en su diario. Aunque en América había ejercido una enérgica protesta pública contra la esclavitud, que tanto le había impactado, en Rusia solo pudo dar tímidas sugerencias para paliarla o bien, en el caso de los deportados, no pudo más que, a título personal, apelar a la piedad del monarca. Del otro lado del Atlántico, Humboldt se encontraba bajo una amplia libertad; tras los Urales, bajo un poder omnisciente y opresor ${ }^{3}$.

La diferencia fundamental entre ambos viajes fue política. La expedición asiática es, en más de un aspecto, el otro viaje de Alexander von Humboldt. En este no se puede observar al muy ejemplar y celebrado librepensador idealista y humanista, sino a uno menos conocido y decididamente complejo. Esta problemática faceta del viajero puede reconstruirse a través de numerosos testimonios, sobre todo en el fruto más importante de esta expedición: los tres tomos de Asia central ${ }^{4}$. ¿A qué precio pudo viajar Humboldt

3 El rey de España había dado a Humboldt el (raro) permiso de explorar sus colonias. Sobre la relación entre Humboldt y Carlos IV véase: Puig-Samper, 1999: 329-355. Puig-Samper y Garrido, 2016: 50-62. Puig-Samper y Rebok, 2004: 56-67.

${ }_{4} \mathrm{El}$ presente ensayo se basa en la nueva edición alemana Humboldt, 2009 a. Todas las citas, sin embargo, se presentan según el original en francés (cuyos saltos de página son res- 
a través de Rusia? Y, ¿logró compensar las dificultades que tuvo que confrontar en este viaje?

El autor de los respectivos Ensayos políticos sobre Cuba y sobre la Nueva España, de los que el primero resultó ser un manifiesto contra la esclavitud ${ }^{5}$, mientras que el segundo concluye con que México era «el país de la desigualdad» ${ }^{6}$, habría de abstenerse de toda observación política en lo que respectaba al imperio de los zares. «Se explica por sí mismo», comentaba tranquilizando al ministro ruso responsable de financiar su expedición, inquieto por los posibles planes del viajero de documentar su viaje, que Humboldt habría de

... limitarse a la naturaleza muerta y evitar todo aquello que tuviese que ver con instituciones humanas, la situación de las clases bajas: lo que un extraño, iletrado en la lengua, pudiese decir al mundo, siempre es atrevido, inexacto, y, ante la maquinaria tan compleja que representan las circunstancias y los derechos ganados de los rangos más altos y las obligaciones de los más bajos, provocante y de ninguna manera útil ${ }^{7}$.

En privado, se quejó a su hermano sobre la forma en que constantemente se le vigilaba: « $\mathrm{Ni}$ hablar del cuidado del gobierno con nuestro viaje, los eternos saludos, la escolta y la avanzada de la policía, administradores, y guardias de cosacos! Sin embargo, ¡no hay por desgracia ni un solo momento para la soledad, ni se puede dar paso alguno sin ser llevado a cuestas como a un enfermo! $\gg^{8}$ Tras el discurso que tuvo que dar ante la Academia Imperial ${ }^{9}$, luego de haber regresado de Siberia y del Mar Caspio, Humboldt mismo admite que ese «grito de Petersburgo» (cri de Pétersbourg) no era más que

petados también en la edición alemana): Humboldt, 1843. Los números romanos indican el tomo, y los arábigos, el número de página.

El artículo además está basado en reflexiones que el autor formuló en el epílogo «Die andere Reise des Alexander von Humboldt», Humboldt, 2009: 845-885. Y en el ensayo «Von Amerika nach Asien. Zehn Thesen über die 'andere Reise' des Alexander von Humboldt», Honold, 2011: 111-132, aquí traducido del alemán por Adrián Herrera.

Sobre la historia del viaje de Humboldt a Rusia, véase: Klencke, 1876: 281-342. Kletke, [1854-1856]. Beck, 1983. Suckow, 2001: 247-264.

5 Humboldt, 1826a, tomo I: 305-336.

6 «Le Mexique est le pays de l'inegalité», Humboldt, 1811, tomo I: 428.

7 Carta a Georg von Cancrin desde Ekaterimburgo del 17 de julio de 1829, en Humboldt y Cancrin, 1869: 65-120. Las referencias en el texto contienen fecha y lugar de las respectivas cartas según esta edición. Véase también la edición sistemática de las cartas del viaje a Rusia: Humboldt, 2009b.

8 Carta a Wilhelm von Humboldt desde Ekaterimburgo del 21 de junio de 1829, en Humboldt, 1880: 165-213. Las referencias en el texto están indicadas según lugar y fecha de las respectivas cartas.

9 Humboldt, 1829: 138-152. 
una «parodia ante la Corte», un «intento de adulación sin sumisión» ${ }^{10}$. Cuando finalmente dedica su voluminoso tratado sobre Asia al Zar, reconoce que «me ha costado un enorme trabajo [...]. Pero tenía que ser así, pues fue bajo su patrocinio que la expedición pudo realizarse ${ }^{11}$. Humboldt sabía que su relación con el autócrata era peligrosa. En su parábola poética sobre «la fuerza de la vida» (Lebenskraft), publicada en las Horen de Schiller en 1795, el entonces joven científico había advertido que «la cercanía al poder despojaba incluso al más fuerte de su espíritu» ${ }^{12}$.

Lo que vivió en su trayecto hacia Rusia, debió haber intranquilizado la conciencia del pensador ilustrado. Gustav Rose, su compañero de viaje, lo atestigua de la siguiente forma:

En ese trayecto vimos por primera vez a un grupo de presos, deportados camino a Siberia. Todas ellas mujeres y niñas, 60 u 80 aproximadamente. Caminaban por su propio pie, lo cual quiere decir que habían cometido crímenes menores. Aquellos que ocurren en crímenes más graves, de los cuales vimos algunos grupos más adelante durante el viaje, caminan formados en dos filas, atados de una mano a una cuerda que cargan por el centro [...]. En cada estación, situadas aproximadamente cada 30 vueltas [una «vuelta de arado» o verstá $=1.0668$ kilómetros] de la ruta principal hacia Siberia, se encuentran algunas casas de madera, cercadas por empalizados, en las cuales los «enviados» (como se les nombra en Rusia a los deportados) pasan la noche, y en las que se detienen a descansar cada cuatro días. No constituye ninguna atracción encontrarlos con frecuencia en la ruta hacia Siberia ${ }^{13}$.

En los diarios de Humboldt, se encuentran notas que sugieren aquello que vio y tuvo que callar: «almas expulsadas», «sin culpa a Siberia» ${ }^{14}$.

¿Qué implica viajar por un país represor?, ¿cómo es posible escribir en un Estado policial? El investigador prusiano compartió el mismo dilema con el que hoy en día se encuentran corresponsales y diplomáticos entre favoritismo e influencia, autorización e intimidación, acceso privilegiado y desinformación, censura y autocensura. Conoció las tensiones de la política económica internacional frente a los derechos humanos, el aseguramiento de recursos naturales e intereses comerciales. El científico transitó entre pretensiones,

10 Carta a Varnhagen von Ense del 26 de abril de 1830, en Humboldt, 1860: 7.

11 Carta a Heinrich Christian Schumacher del 22 de mayo de 1843, en Humboldt y Schumacher, 1979: 112.

12 Humboldt, 1795: 93.

13 Rose, 1837/1842, tomo I: 110-111.

14 Alexander von Humboldt, Fragmente des Sibirischen Reise-Journals, 1829, original, Schloß Tegel, Berlín; fotocopia y transcripción: Alexander von Humboldt-Forschungsstelle der Berlin-Brandenburgischen Akademie der Wissenschaften; reproducción y transcripción selectivas, Humboldt, 2009a: 793, 791. 
exigencias y limitaciones. ¿Cómo reaccionó ante estas circunstancias?, ¿asumió algún compromiso?, ¿o encontró alguna manera de lidiar productivamente con retos complicados? En una situación así de precaria, Humboldt adquirió perspectivas inesperadas, formuló ideas originales y adoptó nuevas formas que aparecen sorprendentes, actuales y estimulantes tanto política, como científica y artísticamente.

Con su viaje por América como trasfondo, pueden formularse diez tesis que reflejan los resultados de su expedición a Asia.

Primera tesis: Como comentarista político, Humboldt desarrolla una TÉCNICA DE CRÍTICA SUTIL QUE PUEDE LEERSE ENTRE LÍNEAS

Como no podía expresarse abiertamente, Humboldt codificó diversas críticas en el texto de su Asie centrale. De este modo, es precisamente su dedicatoria al Zar de una insolencia apenas disimulada. Humboldt atribuye irónicamente al monarca la defensa del libre desarrollo de las «facultades del espíritu». Ya desde el inicio de su obra, el autor aborda la presión a la que habría de someterse recurriendo al sarcasmo y al doble sentido para citar al emperador: él quisiera que «todo aquello que se refiera a intereses materiales y locales tenga solamente un papel secundario en mis investigaciones». La dedicatoria cierra con un agradecimiento a los «poderosos monarcas». ¿Cuán irónicamente se puede entender el afán de libertad cuando se está en deuda con un déspota?

Ya desde el inicio puede intuirse el múltiple sentido del texto. Si en consecuencia se lee esta obra decididamente apolítica con particular atención en las sutiles insinuaciones, se vuelve entonces evidente aquello que no era oportuno o posible abordar de manera directa. En la primera página de la introducción, Humboldt habla de un «levantamiento de las masas» (soulèvement des masses). En apariencia, se refiere a una elevación montañosa. Pero después de su irónica reverencia ante los poderosos, esta metáfora sugiere la posibilidad (y necesidad) de una rebelión, sobre todo si se la relaciona del mismo modo al «estado de las sociedades humanas». Humboldt utiliza así la geología como metáfora política.

Al final de su introducción, menciona directamente a un «Señor Witkiewicz», un «intrépido viajero», sin decir cuáles habían sido sus méritos (I.LIV). Vuelve a hacerlo nuevamente, de manera indirecta, al citar los relatos de otros viajeros, concretamente los de Gregor von Helmersen y Alexander Burnes. El mismo Humboldt se dirige a aquellas «personas en Siberia», sin decir con exactitud a quienes, «que comparten conmigo el interés que me 
despertó el triste y venturado destino de este joven polaco cuando, en septiembre de 1829, pasé por Orsk». Esta cuidadosa mención es verdaderamente explosiva, ya que se trataba de un deportado político por cuya rehabilitación abogó el alemán ante el Zar. Según puede comprobarse en notas añadidas posteriormente en sus diarios, Humboldt siguió de cerca el caso de Witkiewicz tras su regreso a Berlín. Cierra su diario con la lamentable mención de que aquel perseguido político, por cuyo perdón se había comprometido, había muerto finalmente víctima del sistema zarista.

En la primera parte de la obra, la dedicatoria, la imagen del «levantamiento» y la alusión al deportado abren una dimensión política, pero, al mismo tiempo, la disimulan como cortesía, metáfora y cita. Una vez que se identifica esta estrategia, pueden reconocerse varias observaciones críticas dispersas a lo largo del texto: por ejemplo, en referencias a actos de represión, colonización forzada, remuneraciones injustas, esclavitud y a la general sumisión de la sociedad rusa. Humboldt escribió sobre la «Siberia de los condenados» (I.192), sobre «Beresow, la ciudad de los deportados» (II.139), sobre el «muy modesto salario de los trabajadores» (I.314), sobre los «impedimentos» políticos para un desarrollo económico libre (III.191) y sobre los «rápidos progresos» que, en contraste, habían podido lograrse en Occidente gracias a «constituciones sólidas y libres» (III.122). Por otra parte, insinuaciones diversas critican la "política económica» (I.XVI) de Rusia, cuyas condiciones productivas dependían de las propiedades reales y de la esclavitud. No hay que ignorar un hecho: y es que Asie centrale apareció en París en 1843, al mismo tiempo y en el mismo lugar en el que Karl Marx comenzaba a ocuparse de economía política, cinco años antes de la aparición del Manifiesto comunista.

Antes de partir a Asia, en su artículo «Sobre las futuras relaciones entre Europa y América», Humboldt escribió abiertamente, refiriéndose a las colonias españolas: «El despotismo está acompañado, en todo momento, de un empobrecimiento progresivo y una disminución del bienestar público» ${ }^{15}$.

SEgunda tesis: Humboldt PROPONE UNA DiALÉCtiCA DEL COLONIALISMO

El viaje tuvo lugar en el punto de fricción de tres imperios: el ruso, el británico y el chino. Sus predecesores históricos habían sido los grandes reinos de los macedonios, bizantinos, árabes y mongoles. A partir de ellos,

15 Humboldt, 1826b: 134-135. (Véase: Humboldt, 1814 [-1831], tomo III: 56-60.) 
Alexander von Humboldt desarrolla ideas sobre la correlación entre conquista y descubrimiento.

«Las guerras que el Imperio Celestial libró durante varios siglos contra los pueblos de Occidente», explica, «estimularon la curiosidad de los descubridores y favorecieron el desarrollo de la geografía» (II.6). La expansión colonial incrementó los conocimientos topográficos y mejoró la cartografía. La necesidad de una administración eficiente exigió el desarrollo de infraestructura, investigaciones lingüísticas y comunicación. Asimismo, el colonialismo ruso en Asia central tuvo efectos inesperados: "Casualmente, la ambición estimuló el progreso» (I.335). Con respecto a un inminente ataque del Zar contra el Khan de Khiwa, comenta Humboldt, no sin dejar entrever cierto cinismo, que la exploración de aquellas «otrora prósperas regiones» «sacaría provecho» de la avanzada militar (I.420-421). Humboldt reconoce que el conocimiento es el otro lado del poder. El hecho de que haya llegado a esta conclusión a partir de su experiencia en Rusia probablemente no sea mera casualidad.

En el segundo tomo de Kosmos, publicado poco después de Asie centrale, habría de desarrollar estas ideas en una dialéctica global del progreso. Crea así la primera teoría poscolonial en la literatura alemana: La historia de la ciencia es una historia del colonialismo ${ }^{16}$.

TERCERA TESIS: EL CIENTIIFICO ENCUENTRA EN LOS MITOS INDÍGENAS UNA PROPIA FORMA DE CONOCIMIENTO, DE «PENSAMIENTO SALVAJE»

Junto a su dialéctica entre saber y poder, Alexander von Humboldt desarrolla en Asia central una más: aquella de la Ilustración y la mitología. El científico no consideraba los mitos como lo opuesto a lo racional; más bien se preguntaba qué secretos de la sabiduría podrían esconderse en ellos.

En ningún momento tilda de meras supersticiones a prácticas como por ejemplo los sacrificios a espíritus de las montañas o el culto a meteoritos. Las historias de vientos abrasadores y montañas de fuego, mundos de cristal y columnas de hielo, asnos que vuelan y ovejas elevadas por el viento, mismas que aparecen en gran número en Asia central, son para él una forma concreta de conocimiento.

Apenas es posible separar la figura del científico de la de un antropólogo o un mitógrafo. Humboldt mismo documentó varios de estos mitos entre los lo-

16 Humboldt, 1847: 135-520. 
cales, o a través de traducciones de manuscritos que contenían sus relatos. Entre ellos, se encuentra la fábula del pez parlante (II.200), el cuento de unas aves que devoraban hombres (II.95) o la saga de los enanos que resguardaban el oro (II.420, anotación), relatos todos en los que Humboldt identifica una manera de entender la naturaleza. Como científico y literato, se interesaba tanto por las osamentas de camello que yacían a orillas del camino (II.28), como por el método de Bougainville de enviar correo en botellas a través de largas distancias (I.337, anotación), el uso de señales de fuego como una especie de telegrafía (III.373), de capas de hielo como cristales de ventanas (III.50-51), del uso de la fotografía como método para concebir la climatología de la luz (III.108-109). Incluso en otra parte habla sobre la existencia de un muro sobre el cual se decía se encontraban escritas las páginas de todo un libro (II.361).

Alexander von Humboldt considera el supuesto «pensamiento salvaje» de los pueblos indígenas como una forma particular de comprender el mundo. Por ello, prestó una particular atención a aquellas culturas nativas sometidas por los rusos.

CUARTA TESIS: Humboldt BUSCA ALTERNATIVAS A UN DISCURSO ORIENTALISTA

Al llegar a Cumaná y posteriormente escribir sus vivencias de viaje americanas en París, Humboldt sabía que era parte de la tradición europea del encuentro con el «Nuevo Mundo». Del mismo modo, al entrar en territorio ruso y viajar a Asia, Humboldt se concibe a sí mismo como parte de una historia análoga. En Asie centrale reflexiona sobre las siguientes preguntas: ¿Cómo se desarrolló el conocimiento geográfico sobre Asia?, ¿a través de qué rutas entraron los europeos en contacto con Oriente? Y, ¿cómo se posiciona él mismo frente a esta tradición?

A través de un estudio intensivo de fuentes, el filólogo viajero reconstruye una serie de evidencias sobre la imagen europea de Asia, comenzando con la «idea de los antiguos». Uno de los capítulos más bellos lo constituye aquel sobre el mito de los grifos vigilantes del oro (I.389-411). Éste contiene historias increíbles de bárbaros sobre caballos blancos, mamuts monstruosos y seres calvos con narices planas. No obstante, el propósito de Humboldt no era estudiar desde una perspectiva unívoca un conjunto de textos occidentales sobre el Oriente, sino más bien otorgar la palabra a diversos «autores orientales». De este modo, hizo una amplia selección de textos geográficos provenientes de fuentes chinas, cuya traducción puso a cargo de especialistas (II.335-364, 441-488). Entre sus informantes se encuentran, a través de los siglos, autores griegos, geógrafos árabes, viajeros 
italianos, peregrinos tibetanos, colonizadores rusos, militares mongoles y comerciantes bujarianos.

Si bien Asie centrale es parte de un discurso, no puede reducirse a éste. De este modo, Humboldt se distancia de una arqueología que «apenas considera aquel Oriente no bíblico» (II.176). Su aproximación a Asia no puede explicarse según el modelo binario de Edward Said, según el cual las representaciones occidentales del Oriente identifican en éste un eterno «otro», ignorando la realidad y sin prestar atención a fuentes locales ${ }^{17}$. De manera similar, el modelo concéntrico del «paradigma griego», propuesto por V. Y. Mudimbe, según el cual otras culturas aparecen más ajenas y monstruosas entre más geográficamente distantes se encontraran en relación al centro europeo, no le haría justicia a Humboldt ${ }^{18}$. Más adecuadas pueden ser las perspectivas de Martin Bernal ${ }^{19} \mathrm{o}$ de Homi Bhabha ${ }^{20}$ sobre confluencia e hibridación. El trabajo del científico alemán es resultado del interés en influencias mutuas.

QUINTA TESIS: El VIAJE A RUSIA REFINA Y PONE EN PRÁCTICA UN PROGRAMA MULTIDISCIPLINARIO PARA LA INVESTIGACIÓN DEL ESPACIO

En Asia central, Humboldt crea una poética de la frontera y el espacio. Son cinco las demarcaciones a las que llegó durante su expedición. Comenzó en la frontera ruso-prusiana. El límite continental en los Urales lo indicaba, arbitrariamente, un árbol "con la inscripción Europa, Rusia, Asia, Siberia» (I.387-388, anotación). De cuando en cuando aparece en sus diarios, en las cartas y en Asia central su fascinación por la frontera china. De regreso a Occidente, su expedición recorrió la margen meridional del imperio de los zares, misma que legiones de cosacos protegían de los pueblos nómadas. A orillas del Mar Caspio, llegó a una zona de contacto entre diversas culturas: rusos, tártaros, armenios, georgianos, kirguisios, calmucos, indios, judíos. Ahí parecía no haber más fronteras, como si se tratase de un espacio utópico.

¿Cómo puede investigarse un país viajando por él? El equipo de Humboldt se repartía el trabajo. Pero lo innovador no radica solamente en la microbiología de Ehrenberg, la mineralogía de Rose o la climatología de Humboldt. Lo que decididamente resulta innovador es el pensamiento relacional, mismo que Humboldt utilizó como método y que alcanza aquí, durante esta travesía, su perfec-

\footnotetext{
17 Said, 1994 [1978].

18 Mudimbe, 1994: 71-104.

19 Bernal, 1994; 1996; 2006.

20 Bhabha, 1994.
} 
ción. En Asia central se aplican diversas formas de conocimiento en una sola concepción multidisciplinaria del espacio: mineralogía, geología, geografía, cartografía, climatología, zoología, paleontología, botánica, geografía botánica, arqueología, antropología, etnografía, mitología, filología y economía política.

Por otro lado, Humboldt no se limita solamente a los sitios que él mismo había recorrido. Más bien se ocupa en general de toda el Asia central. Pero, ¿de qué manera puede alguien describir todo un continente que apenas es posible atravesar o medir en su totalidad? Humboldt se vale para ello de todos los medios de que dispone: como geólogo, traza la forma de las cadenas montañosas como si se tratara de arte abstracto. Como cartógrafo, se sirve de todos los mapas disponibles para bosquejar una propia topografía. Como geobotánico, investiga la distribución y migración de las plantas. Como climatólogo, analiza las relaciones de tiempo y espacio del frío y del calor, y reparte el mundo en «líneas isotérmicas» que comprenden zonas con temperaturas promedio similares. Como teórico de la cultura, considera la influencia recíproca entre medio ambiente natural y civilización humana. Como paleontólogo, analiza los restos fósiles de animales prehistóricos y, a partir de hallazgos particulares, extrae conclusiones sobre la historia de la Tierra. Como historiador, reconstruye descubrimientos y exploraciones. Como analista geopolítico, delimita las zonas de influencia de grandes potencias. Como viajero, colecciona relatos de viaje y reproduce rutas. Como arqueólogo, explora ruinas y zonas de excavación. Como lingüista, se ocupa de las lenguas de los pueblos indígenas y de las etimologías toponímicas. Como etnógrafo, recava información entre los nativos y encarga traducciones de documentos indígenas. Y como filólogo, analiza fuentes europeas y asiáticas.

Un artículo sobre Alexander von Humboldt en el Conversations-Lexikon Brockhaus (Leipzig) de 1853 destaca que éste llegó a «hallazgos inesperados» tras «combinar varias disciplinas científicas», «que normalmente no se considerarían relacionadas entre sí» ${ }^{21}$.

SEXTA TESIS: EL VIAJERO PERCIBE AL MUNDO TRIANGULARMENTE, CONSIDERANDO AL OTRO NO SOLO EN RELACIÓN A LO CONOCIDO, SINO TAMBIÉN EN FUNCIÓN DE UNA TERCERA CATEGORÍA

La perspectiva de Humboldt es en todo momento doble: a nivel local, detallada y precisa; a nivel global, de una amplia erudición comparativa.

21 Humboldt, 1853, tomo VIII: 130. 
Como comparatista, realiza constantemente analogías, encuentra conexiones que surgen en su propio camino y que van más allá del espacio representado. Es así como en los Urales puede transportarse a la cordillera andina; en el Altai, al Chimborazo; en el Ob, al Orinoco y, en el Mar Caspio, al Valle de México. Su segundo viaje por el mundo está en relación con el primero. El viaje a través de Asia se convierte en un movimiento imaginario por el «Nuevo Mundo». Del mismo modo, en su imaginación fue asimismo su expedición americana un recorrido por Oriente, al cual con frecuencia remite poéticamente en su relato de viaje. Al mismo tiempo, hace de su travesía un viaje en el tiempo por la Antigüedad clásica. Percibe lo ajeno de forma triangular: siempre en relación a un tercer lugar que, comparativamente, ayuda a comprenderlo. Humboldt pensaba en triángulos ${ }^{22}$.

Entre la América hispánica y el Asia central tuvo lugar incluso una transferencia de mitos: un intercambio entre la tierra del Amazonas y El Dorado. Mientras que la idea de un reino dominado por mujeres salvajes, en las márgenes del mundo conocido, pasó de la tierra mítica de los escitios al inmenso río que cruza la selva tropical, el sueño de un lugar repleto de riquezas inmesurables pasa de Venezuela a Siberia. «El Ural es un auténtico Dorado», escribe Humboldt al ministro Cancrin desde Miask (15 de septiembre de 1829).

Siberia es una especie de «Nuevo Mundo» en el «continente viejo», una tierra de fantasía. Tiene una propia historia de ficciones que se origina en la segunda parte del Robinson Crusoe (1719) ${ }^{23}$ de Daniel Defoe y que llega a la actualidad, pasando por el Correo de los Zares (1876) ${ }^{24}$ de Julio Verne. Del mismo modo que Humboldt, Karl May no solo se sentía fascinado por América y el Oriente, sino también por Siberia, a la que dedica un texto del mismo nombre $(1887-1888)^{25}$.

Un punto fijo de referencia lo constituye el lugar de origen. En sus cartas a su hermano en Tegel, Humboldt habla sobre cómo a la distancia había cosas que le parecían sumamente familiares: «Por desgracia, la vegetación es en principio igual a los pastizales de Tegel» (8 de julio de 1829, desde Kasan); «la frontera asiática guarda sin embargo cierta similitud con los prados de Tegel» (21 de junio de 1829, desde Ekaterimburgo). «Regresando de la Mongolia china, Moscú me recuerda a Spandau» (5 de noviembre de 1829, desde

22 Respecto a la técnica triangulatoria de Alexander von Humboldt y la superposición de imágenes de otros espacios en descripciones de regiones recorridas, véase: Lubrich, 2001: 749-766; 2003: 11-29. Ette, 2009: 319-364.

23 Defoe, 1719.

24 Verne, 1876.

25 May, 1996: 304-322. 
Moscú). En su diario se encuentra dos veces la siguiente observación: «Irtisch, cerca de Baty, es más pequeño que el Spree en el Tiergarten ${ }^{26}$. A August Böckh, Humboldt comenta más adelante: «Siberia entera no es más que una continuación de nuestra Hasenheide» [un parque en Berlín] ${ }^{27}$. No se trata aquí de ninguna exotización. Mucho menos de nostalgia.

A inicios del año 1800, se le prohibió a Alexander von Humboldt penetrar en territorio de la Corona portuguesa cuando intentaba explorar la conexión entre los sistemas fluviales del Orinoco y del Amazonas. Tres décadas después consiguió aquello que se le había negado, precisamente en los Urales. Basándose en especulaciones sobre las similitudes geológicas de ambas regiones, asumiendo que la constitución de Siberia era similar a la de Brasil, le aseguró a la Zarina que también ahí se encontrarían diamantes. Y, efectivamente, así fue. De hecho, la evidencia más significativa de aquel viaje es también la más pequeña: el primer diamante jamás encontrado en el «Viejo Mundo». ¿Qué simboliza este diamante? El interés material que motivaba esta expedición. Pero además es la prueba de una atrevida conclusión basada en una analogía, es decir, del método comparativo de Humboldt. Y es, así mismo, un símbolo de la identidad de ambos espacios. Constituye la piedra angular de la así llamada «Disputa sobre el Nuevo Mundo», en la que el mismo Humboldt ya había participado en sus propios escritos sobre América ${ }^{28}$. Sus rivales eran partidarios de un primigenio "anti-americanismo», que afirmaba que el Nuevo Continente había surgido más tarde en la historia geológica de las aguas y que, por lo tanto, era aún un territorio distinto, inmaduro, débil. En los Urales probó, sin embargo, las similitudes entre América y Asia, entre el «nuevo»y el «viejo» mundo.

SÉPTIMA TESIS: EN VEZ DE REPRESENTAR LO AJENO COMO NATURALEZA PURA, HUMBOLDT INVENTA UNA ECOLOGÍA SOCIAL — Y CONCIBE LA TEORÍA DE UN CAMBIO CLIMÁTICO PROVOCADO POR EL HOMBRE

Presuntamente se enfocaría «más en las cosas» que «en las personas», según había prometido Humboldt a su mecenas Cancrin (10 de enero de

${ }^{26}$ Humboldt, Fragmente des Sibirischen Reise-Journals 1829, original, Schloß Tegel, Berlín; fotocopia y transcripción: Alexander von Humboldt-Forschungsstelle der Berlin-Brandenburgischen Akademie der Wissenschaften; reproducción y transcripción selectivas (nota 14), reproducción en: Humboldt, 2009a, (nota 14).

27 Carta a August Böckh, ca. 1840, reproducida en Humboldt, 1901: 418.

28 Gerbi, 1955. 
1829). En efecto, el subtítulo de Asie centrale indica que se trata de una obra de ciencias naturales, específicamente de geología y climatología. ¿Describió Humboldt el continente asiático «solo» como espacio natural?, ¿hizo de él una mera naturaleza salvaje y sin dueños que, por lo tanto, se convertía así en objeto de posesión colonial? Mary Louise Pratt acusa a Humboldt precisamente de esto, basándose en pasajes selectos de sus textos americanos ${ }^{29}$, sin considerar muchos otros fragmentos y obras enteras donde se muestra lo contrario. Sin embargo, en Asie centrale, donde habrían de ignorarse aspectos tanto sociales como políticos, dicha idea, es decir, la de representar el espacio ajeno como naturaleza pura, parece llevarse a cabo consecuentemente.

Aun así, en Asie centrale se representa el intercambio del científico prusiano con otras personas. Humboldt, como invitado de Estado, tuvo principalmente que ver con representantes del gobierno central ruso: con oficiales, soldados, burócratas y administradores de minas. Buscó dialogar con científicos y coleccionistas. Asimismo tuvo contacto con los nativos, con el pueblo común y corriente, con miembros de los pueblos sometidos o de aquellos que aún permanecían sin someter. Así Humboldt habla de su colaboración con líderes locales cerca de Talowka (I.317, anotación), de conversaciones en Oremburgo con viajeros provenientes de los canatos uzbekos (II.81), o de entrevistas que realizó a tártaros y mongoles en Semipalatinsk (II.67-68). En diversas partes de su obra, integra conocimiento local. Dedica incluso un espacio bastante amplio a su encuentro con religiones asiáticas, en particular con el islam y el budismo. De hecho, el librepensador berlinés visitó repetidamente mezquitas y templos, de la misma forma que se interesó por restos arqueológicos de culturas desaparecidas: por ejemplo, las ruinas de Bulghar, las tumbas de los escitas y restos de minas antiguas. Evidentemente sólo lo agobiaban sonidos extraños, por ejemplo, el uso de trompetas y cascabeles durante un ritual religioso calmuco o, «ipor desgracia! También la música vocal de las sultanesas tartáricas» (Carta a Cancrin desde Oremburgo del 26 de septiembre de 1829).

No obstante, incluso limitarse a una «naturaleza inerte» puede tener consecuencias imprevisibles, sobre todo políticas. ¿A qué conclusiones lleva el encuentro con un medio ambiente distinto? Humboldt describe un tsunami (II.544), habla de los primeros intentos de explotación de gas natural (II. 520ff.), y atestigua el efecto del virus del ántrax (en una carta a Cancrin desde Omsk del 27 de agosto de 1829). Aborda cuestiones que hoy recono-

29 Pratt, 1992: 111-143 (anotaciones: 239-242). Zantop, 1997. Para una discusión metodológica véase: Lubrich, 2005: 16-39. 
cemos como ecológicas o, más precisamente, socioecológicas. Durante sus inspecciones mineras, Humboldt concluyó, como especialista en el campo, de que la cantidad y la forma de generar energía tenían consecuencias directas sobre la naturaleza. La ineficiencia en la explotación minera rusa demandaba una alta e innecesaria cantidad de leña combustible, provocando así una extensa «deforestación» (III.199). Humboldt sabía que los bosques y la vegetación conformaban uno de los factores de influencia «más interesantes $\mathrm{y}$, sin embargo, más ignorados» para el clima de un país. A orillas del Mar de Aral, su «progresiva desecación» era evidente, como Humboldt pudo constatar en diversas fuentes (II.138). Este enorme cuerpo de agua, advierte, está «a punto de desaparecer» (II.271). La causa de esto la encontró en las insostenibles prácticas agrícolas de extraer el agua del lago a través de un sistema de canales de riego y en la sobreexplotación de los ríos que lo alimentaban (II.272).

Los fenómenos que tuvieron lugar en los Urales y a orillas del Mar de Aral permitieron a Humboldt formular una teoría de un cambio climático potenciado por la acción humana: «cambios significativos en la calidad de la cubierta terrestre» (atmósfera) habrían ocurrido, resume, como «consecuencia del progreso de las sociedades humanas, en la medida en que estos progresos se pusieron en marcha y se multiplicaron» (III.121). Según Humboldt, podían constatarse «cambios» que habían sido «provocados por el hombre en la superficie del continente, como consecuencia de la tala de bosques, el cambio en el curso de las aguas y en la emisión de grandes cantidades de humo y gases a la atmósfera en aquellos centros de cultura industrial». Finalmente enfatiza: «Estos cambios son más importantes de lo que en general se cree» (III.347).

¿Es este cambio climático, provocado por la generación de energía, la explotación del agua y la contaminación, un fenómeno que se limita a un espacio regional y temporal, o se trata de algo con consecuencias suprarregionales a largo plazo? Precisamente esta es la pregunta que se plantea Humboldt como una cuestión central que «aún ha quedado sin resolver», y que lleva asimismo a la cuestión sobre la «estabilidad de las temperaturas de la Tierra»y, con ello, a plantearse la idea de un calentamiento global. Este reto habría de ser algo que «tendría que asumirse sin limitarse a los efectos locales inmediatos y naturalmente limitados que surgen de la tala de los bosques en valles y montañas y de la desecación de lagos y pantanos» (III.349). Humboldt se veía a sí mismo como defensor de una «climatología general», es decir, de una ciencia ecológica global (III.77). El científico prusiano reconoce así el clima como un fenómeno de escala mundial que puede verse afectado por la acción humana.

Humboldt plantea una respuesta a esta cuestión con un proyecto que coordinaría una serie de investigaciones en todo el mundo, mismo que se 
concretizó en el plan de una red de estaciones de observación. A partir de las experiencias surgidas de problemas locales, consiguió obtener una mirada sobre los retos globales y una propuesta de acción internacional. Asie centrale representa un objeto de estudio ideal para una crítica literaria con un interés ecológico, es decir, para la ecocrítica, en cuyo marco la literatura de viajes puede ser sumamente fértil ${ }^{30}$. La familiaridad con las poco habituales manifestaciones de una naturaleza distinta y con una civilización desconocida aguzó el entendimiento de las correlaciones entre el mundo natural y la acción de los seres humanos. Fue precisamente su enfoque en la naturaleza lo que llevó a Humboldt a la cuestión humana: de un problema científico pasó a uno moral, pues veía en la destrucción de la naturaleza el resultado de una sociedad injusta y de una economía mal administrada.

No obstante, las ideas de Humboldt fueron recibidas con escepticismo. Utilizando el diario de Cristóbal Colón como fuente, el viajero alemán intentó demostrar cómo la deforestación de Haití, ocurrida hacía ya más de tres siglos, había transformado el clima de la isla: «La humedad del aire disminuyó como consecuencia de la destrucción de una parte de los bosques» (I.537538, anotación). Precisamente su traductor y editor alemán, Wilhelm Mahlmann, manifestó su desacuerdo en una nota al pie: «El hecho de que la destrucción de los bosques tenga una influencia relevante [en el cambio del clima], nos parece todavía dudoso basándonos en las investigaciones hechas hasta ahora al respecto» ${ }^{31}$.

OCTAVA TESIS: ALEXANDER VON HUMBOLDT DIALOGA ENASIA CONEL PENSAMIENTO EVOluCiOnista de Charles Darwin

Alexander von Humbolt se mantuvo en diálogo con Charles Darwin durante varias décadas ${ }^{32}$. En Asia central continúa una conversación que su colega, más joven que él (1809-1882), había comenzado tiempo atrás. Durante su último año en Cambridge, Darwin escribió en su Autobiografía, que Humboldt había «despertado en mí el ardiente deseo de hacer aunque fuera la más mínima contribución a la noble estructura de las Ciencias Naturales» (stirred up in me a burning zeal to add even the most humble contribution

\footnotetext{
30 Véase Sachs, 2006.

31 Humboldt, 1844, tomo I: 337.

32 Véase Puig-Samper y Rebok, 2010: 56-65. Werner, 2009: 68-95.
} 
to the noble structure of Natural Science) ${ }^{33}$. Incluso Darwin emprendió su viaje a Sudamérica a bordo del Beagle (1831-1836) bajo la influencia de su antecesor, a quien constantemente menciona en sus cartas. De este modo, escribe el 27 de julio de 1831 que había leído la obra de Humboldt una y otra vez: «Leo y releo a Humboldt» (I read and re-read Humboldt). En una carta del 8 de febrero de 1832, enviada a Inglaterra, aconseja que «si quieres realmente tener una idea de los países tropicales, estudia a Humboldt. Olvídate de las partes científicas, y comienza en la parte en que deja Tenerife. Entre más lo leo, mayor admiración siento por él». (If you really want to have [an idea] of tropical countries, study Humboldt. Skip the scientific parts, and commence after leaving Teneriffe. My feelings amount to admiration the more I read him). Como parte de un plan de preparación para cualquier naturalista, recomendaba «estudiar español, francés, dibujo, y a Humboldt» (study Spanish, French, drawing, and Humboldt). En mayo de 1832, adscribe sus propias investigaciones al modelo científico humboldtiano: «Si tiene que hacerse, entonces será a partir del estudio de Humboldt». (If it is to be done, it must be by studying Humboldt). El 18 de mayo de 1832, Darwin admite en Río de Janeiro: «Antes admiraba a Humboldt, ahora casi le rindo culto. Su sola figura basta para adquirir cualquier noción sobre los sentimientos que nacen en la mente al llegar por primera vez a los trópicos» (I formerly admired Humboldt, I now almost adore him; he alone gives any notion of the feelings which are raised in the mind on first entering the Tropics $)^{34}$. Finalmente, en el relato de su expedición, el Viaje en el Beagle $(1837 ; 1839,1845)$, Darwin resume en qué medida su propio proyecto estuvo bajo la influencia del científico alemán: «Si bien la fuerza de las impresiones generalmente depende de ideas preconcebidas, debo añadir que las mías propias surgieron de las vívidas descripciones en la Narrativa personal de Humboldt, que exceden por mucho en méritos a cualquier otra que haya leído». (As the force of impressions generally depends on preconceived ideas, I may add, that mine were taken from the vivid descriptions in the Personal Narrative of Humboldt, which far exceed in merit anything else which I have read) ${ }^{35}$.

Por su parte, Humboldt responde al científico inglés en su obra sobre Asia. Ahora es él quien hace referencia a Darwin y a su expedición al Nuevo Mundo. Cita a su estudiante y sucesor una docena de veces, lo cual resulta más notorio considerando que éste no había estado en las regiones asiáticas que

\footnotetext{
33 Darwin, 1887, tomo I: 55.

34 Ibidem: 190, 231, 232, 234, 236.

35 Darwin, 1845, tomo III: 503.
} 
él describía. Sus citas vienen acompañadas de grandes elogios: «exactas observaciones», «agudas consideraciones», «importante obra», «descrito pintorescamente». El contexto lo conforman aquellas ciencias que eran centrales para Humboldt: geología, climatología, geografía de las plantas y de los animales. Consulta a Darwin sobre la extensión del continente americano a través de diversas zonas climáticas (III.168), sobre los límites de las nieves en las montañas (III.329, 333, 334, 337), sobre la fertilidad de la vegetación tropical (III.180-181), o sobre la migración de las especies animales a otras regiones (I.340; III.99, 183). Asimismo, esboza ideas que se asemejan a una teoría de la evolución, mismas que Darwin aún todavía no publicaba: por ejemplo, sobre la extinción de las especies, sobre la sobrevivencia del más fuerte y sobre su adaptación por aclimatación (III.92, 98-99). También esto es resultado de una escritura indirectamente política, con su expedición a América en el trasfondo.

NOVENA TESIS: DESDE UN PUNTO DE VISTA ESTÉTICO, HUMBOLDT EVITA LOS FORMATOS CONVENCIONALES DEL DIARIO, DEL RELATO DE VIAJES Y DE LA AUTOBIOGRAFÍA. ASIE CENTRALE DECONSTRUYE LA LITERATURA DE VIAJES

¿Cómo relata Alexander von Humboldt su viaje por Asia? En cierto sentido, no cuenta nada. Por lo menos no de la forma que se esperaría. No hay ningún inicio ni ningún final, ni partida ni regreso, ninguna ruta, ningún viajero. El viajero desaparece tras la realidad del viaje. A la cuestión de cómo abordarlo, el escritor responde con un esbozo radical: No se debe narrar su secuencia y se debe hablar lo menos posible de sí mismo, de sus actividades propias y de sus vivencias casuales.

Solo aisladamente deja ver sus experiencias en impresiones, episodios, núcleos narrativos y anécdotas fragmentadas. Humboldt habla de trayectos agotadores en incómodas carrozas (III.488) a través de caminos en malas condiciones (I.321), del cruce de la «terrible» estepa de Baraba (II.138), de su recorrido a lo largo de la frontera sur, resguardada por cosacos (II.125), y de su travesía en bote en el Mar Caspio (II.148); de la escalada de un monte cubierto de hierbas tan altas como un ser humano (I.323) y de sus observaciones atentas en plena naturaleza, bajo tormentas de nieve (III.454). Habla también de su encuentro con un guardia en la frontera con China (I.295, 332), de su interacción con los tártaros (III.379, anotación), de su visita al Príncipe de los Calmucos (II.16-17, anotación) y de su relación con el sultán de una tribu en el interior de Kirguistán (II.129, anotación). Así, 
Humboldt fractura su propio relato en miles de fragmentos repartidos a lo largo del texto.

Más que poder identificar un formato convencional, es posible reconocer lo que esta obra precisamente no es o no debe ser: un relato de viaje, un diario o una autobiografía. Humboldt rechaza lo usual. Reproduce solo en un fragmento «algunas páginas de mi diario de viaje por Asia» (I.297-309). Curiosamente estas páginas no corresponden a ninguna parte de los diarios que se conservan. Es de suponer que aquí simplemente imitó el formato de un diario sin citar realmente párrafos auténticos. De esta manera, Humboldt contrasta su representación con los formatos tradicionales, dejando ver así qué tan lejos se encontraba su propio texto de las convenciones.

Los primeros dos textos de su obra de tres tomos, la dedicatoria y la introducción, se asemejan al género ensayístico, característico de la escritura experimental de Humboldt y de la obra abierta que ésta crea: «J'ai essayé», es decir, literalmente, «ensayé», «intenté». El autor viajero aquí realmente «ensaya» escribiendo de otra forma sobre su estancia en un país extranjero en comparación con lo que hasta entonces se solía hacer. En ambos textos, comienza con el pronombre «Yo» (como sucedería más adelante en Kosmos). No obstante, se trata aquí de todo menos del comienzo de una autobiografía. Asie centrale es, por el contrario, la antítesis de una narración biográfica. En su transcurso, apenas aparece la primera persona de un viajero o, en el trasfondo, alguna figura semejante a un narrador.

Para evadir las formas de la literatura de viajes, Humboldt concluye con un detalle provocador. El relato coherente de su expedición lo deja a otros. No lo narra él mismo, sino que refiere al lector al «relato histórico» de Gustav Rose, mientras que al final de su propia obra, cita una «breve nota sobre mi viaje» que ni siquiera llega a las diez páginas, extraída de una publicación de Cuvier, en la que él mismo aparece en tercera persona: «Reporte histórico sobre el viaje del señor Alexander von Humboldt a Siberia» ${ }^{36}$ (III.599-608).

36 Alexander von Humboldt ya había fragmentado el relato autobiográfico, renunciado a la narración y roto las convenciones de la literatura de viajes en obras anteriores. En Asie centrale continuó experimentando con estas técnicas. El desarrollo de Humboldt como autor permite entender su libro sobre Rusia. Tiende a la abstracción progresiva. El enfoque se transfiere cada vez más del viajero hacia el espacio viajado. La linearidad biográfica e itineraria desaparece. Las poéticas se trasforman desde el enfoque geográfico del género epistolar y del diario a la descripción de una ruta determinada, vistas de paisajes y descripciones de fenómenos aislados hacia la representación de un país, un continente y hasta de la Tierra y del Universo. La perspectiva se amplía desde la meramente biográfica, pasando por la regional o nacional, para convertirse en una continental y, finalmente, en una visión global e incluso 
DÉCIMA TESIS: EN SU POLÍTICA DE LA FORMA, HUMBOLDT SUSTITUYE MONÓLOGO CON POLIFONÍA Y PERSPECTIVA CENTRAL CON PRISMATISMO

Asie centrale es un texto científico y, al mismo tiempo, literario. Cuando Alexander von Humboldt recorre la «extensión de la vida desde los picos relucientes de nieve hasta las oscuras profundidades del mar» (I.LVIII), o cuando describe cómo el viento sobre la hierba esteparia dispersa las hojas rasgadas de un manuscrito tibetano ante las ruinas de un monasterio (I.336337), lo hace como investigador y como autor. ¿Qué clase de libro es Asie centrale que se presenta a sí mismo como una obra de ciencias naturales pero que, negando toda convención narrativa, está repleto de pasajes poéticos?

Primero que nada, no se trata solamente de la obra de Humboldt, sino del resultado del trabajo de varios autores. Nos enfrentamos a un texto colectivo. Humboldt ha montado numerosos elementos ajenos en su propia presentación: traducciones de fuentes asiáticas de Jaubert, Julien, Klaproth, Klostermann y Korolenko, descripciones indígenas de rutas (III.361-439), el relato de viaje del jefe de una tribu kirguisa (III.422-430), una carta del erudito persa Kazim-beg (II.493-497), pasajes de Fedorow (I.547-548), Verneuil (I.550-551), Helmersen (III.527-529) y Rose (I.500-501, 552-554; III.524-527), ensayos completos de Lenz sobre los volcanes de lodo y los fuegos de Baku (II.505515), de Valenciennes sobre los lobos marinos del Mar Caspio (II.516-550), así como «anejos» de Julien (II.551-552) y el «relato histórico» de Cuvier (III.599-608), además de datos de Mahlmann y un mapa hecho por Petermann, no se diga de innumerables citas de Herodoto y Menandro, entre muchos otros. En parte, las contribuciones de diversos autores apenas pueden distinguirse entre sí. Asie centrale es una obra polifónica.

Y del mismo modo en que es imposible atribuirla a una sola pluma, tampoco se le puede asignar a un único género literario. Asie centrale es plan y teoría, ensayo literario y descripción paisajística, tratado científico y antología. Se trata aquí de una obra que sobrepasa las fronteras entre las formas, de un texto auténticamente híbrido.

Esta manera de escribir sobre un país extranjero contiene un mensaje político. Humboldt contempla su objeto desde diversas perspectivas, a través de los ojos de personas distintas. No lo construye uniformemente, sino como un

universal. Asie centrale tiene una función clave en la obra de Alexander von Humboldt. Este estudio, que durante mucho tiempo fue prácticamente ignorado, representa el nexo entre la obra americana de Humboldt y su Kosmos. Este último proyecto, que pretendía abarcar «el mundo entero en un solo libro», está anticipado aquí en Rusia y en el Asia central en la dimensión de un continente. 
prisma: según la perspectiva desde la que se le lea, el resultado es distinto. Humboldt no cuenta su relato de manera lineal; no representa el Asia central desde una perspectiva céntrica: su obra es todo menos ego y eurocéntrica; es lo contrario a un discurso hegemónico ${ }^{37}$.

Alexander von Humboldt logra así obtener literaria, científica y políticamente una rica cosecha de su viaje por Rusia, misma que logra trascender los desafíos que éste trajo consigo. Aquello que había podido comenzar en América bajo condiciones más favorables, pudo continuarlo en Rusia, evadiendo creativamente las dificultades que se cernían sobre él. Los resultados compensan lo problemático de la empresa.

\section{BiBLIOGRAFÍA}

Beck, Hanno, Alexander von Humboldts Reise durchs Baltikum nach Rußland und Sibirien 1829, Stuttgart/Viena/Berna, Erdmann, 1983.

Bernal, Martin, Black Athena: The Afroasiatic Roots of Classical Civilization, New Brunswick, Rutgers University Press, 1994, 1996, 2006, 3 tomos.

Bhabha, Homi, The Location of Culture, Londres/Nueva York, Routledge, 1994.

Cannon, Susan Faye, "Humboldtian Science", Science in Culture: The Early Victorian Period, Kent/Nueva York, Dawson/Science History Publications, 1978: 73-110.

Darwin, Charles, Journal of Researches Into the Natural History and Geology of the Countries Visited During the Voyage of H. M. S. Beagle Round the World, Under the Command of Capt. Fitz Roy, R. N., Londres, John Murray, 1839, 3 tomos. [Segunda edición en 1845].

Darwin, Charles, The Life and Letters of Charles Darwin, Including an Autobiographical Chapter, editado por Francis Darwin, Londres, John Murray, 1887, 3 tomos.

Defoe, Daniel, The Farther Adventures of Robinson Crusoe, Londres, J. Roberts, 1719.

Dusen, Robert Van, The Literary Ambitions and Achievements of Alexander von Humboldt, Berna/Frankfurt, Peter Lang, 1971.

Ette, Ottmar, Weltbewußtsein. Alexander von Humboldt und das unvollendete Projekt einer anderen Moderne, Weilerswist, Velbrück, 2002.

Ette, Ottmar, Alexander von Humboldt und die Globalisierung, Frankfurt, Insel, 2009.

37 Sobre la deconstrucción del relato de viajes, véase Lubrich, 2004: 360-387. Sobre Humboldt como autor y sobre su idea de la ciencia, véase Dusen, 1971. Cannon, 1978: 73-110. Ette, 2002. Hey'l, 2007. 
Gerbi, Antonello, La disputa del Nuovo Mondo. Storia di una polemica, 1750-1900, Milán/Napolés, Riccardo Ricciardi, 1955.

Hey'l, Bettina, Das Ganze der Natur und die Differenzierung des Wissens. Alexander von Humboldt als Schriftsteller, Berlín/Nueva York, Walter de Gruyter, 2007.

Honold, Alexander (coord.), Ost-westliche Kulturtransfers. Orient-Amerika, Bielefeld, Aisthesis, 2011.

Humboldt, Alexander von, "Die Lebenskraft oder der Rhodische Genius. Eine Erzählung”, Die Horen, 1/5 (Tubinga, 1795): 90-96.

Humboldt, Alexander von, Essai politique sur le royaume de la Nouvelle-Espagne, París, Schoell/Stone [1808-]1811 y [1809-]1811, 2 tomos.

Humboldt, Alexander von, Relation historique du Voyage aux régions équinoxiales du Nouveau Continent, París, F. Schoell, 1814 [-1817], N. Maze, 1819[-1821], J. Smith et Gide Fils, 1825 [-1831], 3 tomos.

Humboldt, Alexander von, Essai politique sur l'île de Cuba, París, Gide fils, 1826a, 2 tomos.

Humboldt, Alexander von, "Ueber die künftigen Verhältnisse von Europa und Amerika", Morgenblatt für gebildete Stände, 20/33 (Stuttgart/Tubinga, 8 de febrero 1826b): 129-130 y 20/34 (9 de febrero 1826b): 134-135.

Humboldt, Alexander von, "Discours prononcé par M. Alexandre de Humboldt à la Séance extraordinaire de l'Académie Impériale des sciences de St.-Pétersbourg tenue le 16/28 Novembre 1829", Hertha, 14 (Stuttgart/Tubinga, 1829): 138-152.

Humboldt, Alexander von, Asie centrale. Recherches sur les chaînes de montagnes et la climatologie comparée, París, Gide, 1843, 3 tomos.

Humboldt, Alexander von, Central-Asien. Untersuchungen über die Gebirgsketten und die vergleichende Klimatologie, traducido y editado por Wilhelm Mahlmann, Berlín, Carl J. Klemann, 1844, 3 partes en 2 tomos.

Humboldt, Alexander von, "Geschichte der physischen Weltanschauung. Hauptmomente der allmäligen Entwickelung und Erweiterung des Begriffs vom Kosmos, als einem Naturganzen", Kosmos. Entwurf einer physischen Weltbeschreibung, Stuttgart/Tubinga, J. G. Cotta, 1847, tomo II: 135-520.

"Humboldt, Alexander von (Friedr. Heinr. Alexander, Freiherr von)", Allgemeine deutsche Real-Encyklopädie für die gebildeten Stände. Conversations-Lexikon, Leipzig, Brockhaus, 1853, tomo VIII: 126-133.

Humboldt, Alexander von, Briefe von Alexander von Humboldt an Varnhagen von Ense aus den Jahren 1827 bis 1858, Leipzig, F. A. Brockhaus, 1860.

Humboldt, Alexander von, Briefe Alexander's von Humboldt an seinen Bruder Wilhelm, editado por la familia von Humboldt en Ottmachau, Stuttgart, J. G. Cotta, 1880. 
Humboldt, Alexander von, "Briefe von Alexander v. Humboldt", Max Hoffmann, August Böckh. Lebensbeschreibung und Auswahl aus seinem wissenschaftlichen Briefwechsel, Leipzig, B. G. Teubner, 1901: 411-454.

Humboldt, Alexander von, Zentral-Asien. Untersuchungen zu den Gebirgsketten und zur vergleichenden Klimatologie, editado por Oliver Lubrich, Frankfurt, S. Fischer, 2009a.

Humboldt, Alexander von, Briefe aus Russland 1829, editado por Eberhard Knobloch, Ingo Schwarz y Christian Sukkow, Berlín, Akademie, $2009 \mathrm{~b}$.

Humboldt, Alexander von y Cancrin, Georg von, Im Ural und Altai. Briefwechsel zwischen Alexander von Humboldt und Graf Georg von Cancrin aus den Jahren 1827-1832, editado por W. v. Schneider y F. Russow, Leipzig, F. A. Brockhaus, 1869.

Humboldt, Alexander von y Schumacher, Heinrich Christian, Briefwechsel zwischen Alexander von Humboldt und Heinrich Christian Schumacher, editado por Kurt-R. Biermann, Berlín, Akademie, 1979.

Klencke, Hermann, Alexander von Humboldt's Leben und Wirken, Reisen und Wissen. Ein biographisches Denkmal, Leipzig, Otto Spamer, 1876.

Kletke, Hermann, Alexander von Humboldt's Reisen in Amerika und Asien. Eine Darstellung seiner wichtigsten Forschungen, tomos III-IV: Alexander von Humboldt's Reisen im europäischen und asiatischen Russland, Berlín, Hasselberg, 1854-1856.

Lubrich, Oliver, “'Como antiguas estatuas de bronce'. Sobre la disolución del clasicismo en la Relación histórica de un Viaje a las regiones equinocciales del Nuevo Mundo de Alejandro de Humboldt", Revista de Indias, 61/223 (Madrid, 2001): 749-766.

Lubrich, Oliver, “'A la manera de los beduinos'. Alejandro de Humboldt 'orientaliza' a América", Casa de las Américas, 232 (La Habana, 2003): 11-29.

Lubrich, Oliver, "Alexander von Humboldt: Revolutionizing Travel Literature", Monatshefte, 96/3 (Madison, 2004): 360-387.

Lubrich, Oliver, "Welche Rolle spielt der literarische Text im postkolonialen Diskurs?", Archiv für das Studium der neueren Sprachen und Literaturen, 157/242 (Berlin, 2005): 16-39.

May, Karl, "Nach Sibirien”, Am Stillen Ocean. Erzählungen (1887-1888), Zürich, Haffmans, 1996: 304-322.

Mudimbe, V. Y., "The Power of the Greek Paradigm”, The Idea of Africa, Bloomington, Indiana University Press, 1994: 71-104.

Pratt, Mary Louise, "Alexander von Humboldt and the reinvention of América", Imperial Eyes. Travel Writing and Transculturation, Londres/Nueva York, Routledge, 1992: 111-143, (anotaciones: 239-242).

Puig-Samper, Miguel Ángel, "Alejandro de Humboldt, un prusiano en la corte de Carlos IV”, Revista de Indias, 216 (Madrid, 1999): 329-355. 
Puig-Samper, Miguel Ángel (coord.), “Alejandro de Humboldt y el mundo hispánico. La Modernidad y la Independencia americana”, Debate y perspectivas 1, Madrid, Mapfre, 2000.

Puig-Samper, Miguel Ángel y Garrido, Elisa, "The presentation of the results of Alexander von Humboldt's voyage to Carlos IV", HiN. International Review for Humboldt Studies, XVII/32 (Potsdam, 2016): 50-62.

Puig-Samper, Miguel Ángel y Rebok, Sandra, "Un sabio en la meseta: el viaje de Alejandro de Humboldt a España en 1799", Revista de Occidente, 254-255 (Madrid, 2002): 95-125.

Puig-Samper, Miguel Ángel y Rebok, Sandra, "Virtuti et merito. El reconocimiento oficial de Humboldt en España", HiN. International Review for Humboldtian Studies, V/8 (Potsdam, 2004): 56-67.

Puig-Samper, Miguel Ángel y Rebok, Sandra, Sentir y medir. Alexander von Humboldt en España, Madrid, Doce Calles, 2007.

Puig-Samper, Miguel Ángel y Rebok, Sandra, "Charles Darwin and Alexander von Humboldt: An exchange of looks between two famous naturalists", HiN. International Review for Humboldt Studies, XI/21 (Potsdam, 2010): 56-65.

Rose, Gustav, Reise nach dem Ural, dem Altai und dem Kaspischen Meere auf Befehl Sr. Majestät des Kaisers von Russland im Jahre 1829 ausgeführt von A. von Humboldt, G. Ehrenberg und G. Rose. Mineralogisch-geognostischer Theil und historischer Bericht der Reise, Berlín, Sandersche Buchhandlung (G. E. Reimer), 1837, 1842, 2 tomos.

Sachs, Aaron, The Humboldt Current. Nineteenth-Century Exploration and the Roots of American Environmentalism, Nueva York, Viking, 2006.

Said, Edward, Orientalism, Nueva York, Vintage, 1994 [1978].

Suckow, Christian, "Alexander von Humboldt und Rußland", Ottmar Ette, Ute Hermanns, Bernd M. Scherer y Christian Suckow (eds.), Alexander von Humboldt. Aufbruch in die Moderne, Berlín, Akademie, 2001: 247-264.

Verne, Jules, Michel Strogoff. Moscou-Irkoutsk, París, J. Hetzel, 1876.

Werner, Petra, "Zum Verhältnis Charles Darwins zu Alexander v. Humboldt und Christian Gottfried Ehrenberg", HiN. International Review for Humboldt Studies, X/18 (Potsdam, 2009): 68-95.

Zantop, Susanne, Colonial Fantasies. Conquest, Family, and Nation in Precolonial Germany, 1770-1870, Durham/Londres, Duke University Press, 1997.

Fecha de recepción: 2 de marzo de 2017.

Fecha de envío de las modificaciones: 19 de junio de 2017.

Fecha de aceptación: 21 de junio de 2017. 


\section{From America to Asia. Alexander von Humboldt's "Other Voyage"}

In 1829, Alexander von Humboldt went on an expedition to Asia. The German naturalist's second great journey is in many ways complementary to his American voyage of 1799-1804. In Russia, Humboldt travelled and worked under conditions of political pressure. His Central Asia (1843) displays subtle techniques of indirect criticism. He observed that inefficient energy production in an economy dominated by state monopolies damaged the environment and led to man-made climate change.

KeY WoRDs: Alexander von Humboldt; Russia; expedition; orientalism; politics; climatology. 